\title{
Pharmacodynamic Effects of a 6-Hour Regimen of Enoxaparin in Patients Undergoing Primary Percutaneous Coronary Intervention (PENNY PCI Study)
}

\author{
Wael Sumaya $^{1,2}$ William A. E. Parker ${ }^{1,2}$ Rebekah Fretwell ${ }^{1}$ Ian R. Hall ${ }^{1,2}$ David S. Barmby ${ }^{1,2}$ \\ James D. Richardson ${ }^{1,2}$ Javaid Iqbal ${ }^{1,2}$ Zulfiquar Adam,2 Kenneth P. Morgan ${ }^{1}$ Julian P. Gunn ${ }^{1,2}$ \\ Annah E. Mason ${ }^{1,2}$ Heather M. Judge ${ }^{1,2}$ Christopher P. Gale ${ }^{3}$ Ramzi A. Ajjan ${ }^{3}$ Robert F. Storey ${ }^{1,2}$
}

\footnotetext{
${ }^{1}$ Department of Infection, Immunity and Cardiovascular Disease, Sheffield Medical School, University of Sheffield, Sheffield, United Kingdom

${ }^{2}$ South Yorkshire Cardiothoracic Centre, Northern General Hospital, Sheffield Teaching Hospitals NHS Foundation Trust, Sheffield, United Kingdom

${ }^{3}$ Leeds Institute of Cardiovascular and Metabolic Medicine, University of Leeds, Leeds, United Kingdom
}

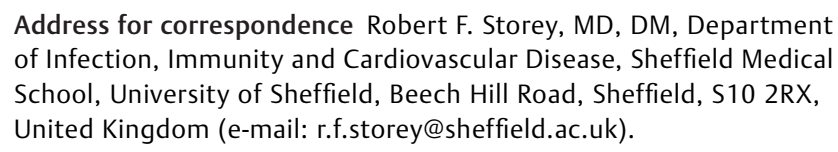

Address for correspondence Robert F. Storey, MD, DM, Department of Infection, Immunity and Cardiovascular Disease, Sheffield Medical School, University of Sheffield, Beech Hill Road, Sheffield, S10 2RX, United Kingdom (e-mail: r.f.storey@sheffield.ac.uk).

Thromb Haemost 2018;118:1250-1256.

\begin{abstract}
Keywords

- STEMI

- primary $\mathrm{PCl}$

- enoxaparin

- P2Y 12 inhibition

- stent thrombosis

Delayed onset of action of oral P2 $\mathrm{Y}_{12}$ inhibitors in ST-elevation myocardial infarction (STEMI) patients may increase the risk of acute stent thrombosis. Available parenteral anti-thrombotic strategies, to deal with this issue, are limited by added cost and increased risk of bleeding. We investigated the pharmacodynamic effects of a novel regimen of enoxaparin in STEMI patients undergoing primary percutaneous coronary intervention (PPCl). Twenty patients were recruited to receive $0.75 \mathrm{mg} / \mathrm{kg}$ bolus of enoxaparin (pre-PPCl) followed by infusion of enoxaparin $0.75 \mathrm{mg} / \mathrm{kg} / 6 \mathrm{~h}$. At four time points (pre-anti-coagulation, end of $\mathrm{PPCl}, 2-3$ hours into infusion and at the end of infusion), anti-Xa levels were determined using chromogenic assays, fibrin clots were assessed by turbidimetric analysis and platelet $\mathrm{P}_{2} \mathrm{Y}_{12}$ inhibition was determined by VerifyNow P2Y12 assay. Clinical outcomes were determined 14 hours after enoxaparin initiation. Nineteen of 20 patients completed the enoxaparin regimen; one patient, who developed no-reflow phenomenon, was switched to tirofiban after the enoxaparin bolus. All received ticagrelor $180 \mathrm{mg}$ before angiography. Mean ( \pm standard error of the mean) anti-Xa levels were sustained during enoxaparin infusion $(1.17 \pm 0.06 \mathrm{IU} / \mathrm{mL}$ at the end of $\mathrm{PPCl}$ and $1.003 \pm 0.06 \mathrm{IU} / \mathrm{mL}$ at 6 hours), resulting in prolonged fibrin clot lag time and increased lysis potential. Onset of platelet $\mathrm{P}_{2} \mathrm{Y}_{12}$ inhibition was delayed in opiate-treated patients. No patients had thrombotic or bleeding complications. In conclusion, enoxaparin $0.75 \mathrm{mg} / \mathrm{kg}$ bolus followed by $0.75 \mathrm{mg} / \mathrm{kg} / 6 \mathrm{~h}$ provides sustained anti-Xa levels in $\mathrm{PPCl}$ patients. This may protect from acute stent thrombosis in opiate-treated $\mathrm{PPCl}$ patients who frequently have delayed onset of oral $\mathrm{P}_{2} \mathrm{Y}_{12}$ inhibition.
\end{abstract}

received

January 29, 2018

accepted after revision

April 26, 2018
DOI https://doi.org/

10.1055/s-0038-1657768.

ISSN 0340-6245. (c) 2018 Georg Thieme Verlag KG Stuttgart · New York
License terms

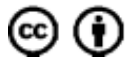




\section{Introduction}

Dual oral anti-platelet therapy is essential in patients presenting with ST-elevation myocardial infarction (STEMI) and undergoing primary percutaneous coronary intervention (PPCI). ${ }^{1}$

Potent $\mathrm{P}_{2} \mathrm{Y}_{12}$ inhibition, with prasugrel or ticagrelor, resulted in improved outcomes following acute coronary syndrome. ${ }^{2,3}$ Although these two agents provide rapid platelet inhibition in stable patients, ${ }^{4,5}$ their onset of action can be delayed in patients undergoing PPCI, particularly those pretreated with opiates such as morphine. ${ }^{6-10}$ This negative interaction might increase the risk of acute stent thrombosis, ${ }^{11}$ necessitating initial parenteral anti-thrombotic treatment to cover the period prior to $\mathrm{P}_{2} \mathrm{Y}_{12}$ inhibitor absorption.

Available parenteral therapies to deal with this issue include glycoprotein IIb/IIla inhibitors (GPIs) ${ }^{12}$ or intravenous $\mathrm{P} \mathrm{Y}_{12}$ inhibition with cangrelor. ${ }^{13}$ However, these options have several limitations. GPIs increase the risk of major bleeding events and routine use has resulted in worse outcomes in several trials. ${ }^{14-17}$ Cangrelor has some advantages: It inhibits platelet $\mathrm{P}_{2} \mathrm{Y}_{12}$ receptors within 2 minutes and has rapid offset of action over 1 hour after cessation of infusion. ${ }^{13}$ However, it has primarily been used as a 2-hour infusion and this might not be sufficient in patients with more than 2 hours delay in the onset of oral $\mathrm{P}_{2} \mathrm{Y}_{12}$ inhibition. Moreover, the very rapid offset of action may pose a risk should the infusion be interrupted. GPIs and cangrelor are costly, another factor that is likely to limit widespread routine use.

Enoxaparin, a low-molecular-weight heparin, targets factor Xa and, to a lesser extent, factor IIa (thrombin). ${ }^{18}$ It has a half-life of 1.5 to 2 hours when given intravenously ${ }^{19}$ and provides more predictable anti-thrombotic effect compared with unfractionated heparin (UFH), negating the need for monitoring. ${ }^{20}$ A bolus dose of 0.5 or $0.75 \mathrm{mg} / \mathrm{kg}$ of enoxaparin can be given to support the PPCI procedure. ${ }^{1}$ In addition to blocking coagulation through the formation of fibrin, heparins inhibit platelet activation by opposing the action of thrombin, ${ }^{21}$ which activates platelets via proteaseactivated receptors 1 and $4 .^{22}$ UFH paradoxically increases platelet reactivity to soluble agonists such as adenosine diphosphate, representing potentially undesirable effects in patients undergoing $\mathrm{PCI}$, whereas therapeutic concentrations of enoxaparin have minimal impact on this. ${ }^{23,24}$

In the ATOLL trial, ${ }^{25}$ a bolus dose of enoxaparin $0.5 \mathrm{mg} / \mathrm{kg}$ (with additional $0.25 \mathrm{mg} / \mathrm{kg}$ for prolonged procedures) in patients undergoing PPCI resulted in comparable results to a bolus dose of UFH (50-70 IU/kg with GPIs or 70-100 IU/kg without GPIs). However, over $75 \%$ of all patients received GPIs. It may, therefore, be more appropriate to use a higher bolus dose of anti-coagulant when GPIs are not used, as was previously acknowledged when studying the combination of UFH with GPI. ${ }^{26}$

We hypothesized that an infusion of enoxaparin $(0.75 \mathrm{mg} /$ $\mathrm{kg} / 6 \mathrm{~h}$ ) following a bolus dose of $0.75 \mathrm{mg} / \mathrm{kg}$ would provide sufficient and sustained anti-thrombotic effects to bridge treatment with oral $\mathrm{P}_{2} \mathrm{Y}_{12}$ inhibition in STEMI patients undergoing PPCI, without the need for GPIs or cangrelor. In this study, we aimed to assess the pharmacodynamic effects of this regimen.

\section{Materials and Methods}

\section{Study Design}

This was a single-centre, single-arm, open-label pharmacodynamic study. All study patients provided informed verbal consent pre-PPCI followed by written consent as soon as possible following PPCI according to a protocol approved by the local research ethics committee and the Medicines and Healthcare Products Regulatory Agency, UK. The trial was registered at http://clinicaltrials.gov (unique identifier: NCT03146858).

In vitro studies of the inhibitory effects of enoxaparin on thrombin-induced platelet activation were also performed to support the rationale for the clinical study. Detailed methods and results of these in vitro studies are reported in the -Supplementary Material (available in the online version).

\section{Study Population and Intervention}

Patients presenting with STEMI and accepted for PPCI were recruited if they met the inclusion and exclusion criteria as detailed in the - Supplementary Material (available in the online version). All patients were pre-treated with ticagrelor $180 \mathrm{mg}$ on arrival to hospital and before angiography. Following angiography, an intra-arterial bolus of enoxaparin $0.75 \mathrm{mg} /$ $\mathrm{kg}$ was administered and an intravenous infusion of $0.75 \mathrm{mg} /$ $\mathrm{kg} / 6 \mathrm{~h}$ was started. For the infusion, enoxaparin $(0.75 \mathrm{mg} / \mathrm{kg})$ was added to $250 \mathrm{~mL}$ of normal saline and started through an infusion pump at a rate of $42 \mathrm{~mL} / \mathrm{h}$. We planned to stop the infusion at 3 hours in cases of significant renal impairment (estimated glomerular filtration rate [eGFR] $<30 \mathrm{~mL} / \mathrm{min} / \mathrm{h}$ ). Only in cases of no-reflow was GPI use permitted and enoxaparin infusion was to be stopped if a GPI was administered. Concomitant use of other anti-coagulants was prohibited and patients were excluded if they had received UFH or another anti-coagulant prior to the procedure.

Blood was collected into citrated tubes at four time points: pre-anti-coagulation, at the end of PPCI, 2 to 3 hours into infusion and at the end of infusion. Clinical outcomes were determined at least 14 hours after initiation of infusion. Outcomes of interest were any thrombotic or bleeding complications.

\section{Pharmacodynamic Measurements}

Tissue factor was obtained from Stago, recombinant tissue plasminogen activator (tPA) from Technoclone, sodium chloride from Sigma-Aldrich and calcium chloride dehydrate and Tris from Fisher Scientific.

Plasma was derived and stored at $-80^{\circ} \mathrm{C}$ until analysis. The primary outcome measure was anti-Xa levels at the three time points during the infusion. Anti-Xa levels were measured using chromogenic assays utilizing the commercially available Coamatic kit (Chromogenix) and Sysmex CS-5100 analyser.

Fibrin clot properties were assessed using a validated turbidimetric assay. ${ }^{27,28}$ Permeation buffer solution $(100 \mathrm{mM} \mathrm{NaCl}$, $50 \mathrm{mM}$ Tris, $\mathrm{pH}$ 7.4) was used for dilution. A total of $25 \mu \mathrm{L}$ of 
plasma (in duplicates) was mixed with $75 \mu \mathrm{L}$ of the activation and lysis mix (83 ng/mL tPA, $10 \mathrm{pM}$ tissue factor, $17 \mathrm{mM}$ calcium chloride; final concentrations) at $37^{\circ} \mathrm{C}$. Multiskan FC (Thermo Scientific) was used to read plates every 30 seconds at $340 \mathrm{~nm}$ until lysis of all samples. Fibrin clot lag time, maximum turbidity (a measure of fibrin clot density, expressed as arbitrary units [AU]) and lysis time (time taken for turbidity to drop by $50 \%$ ) were recorded.

Platelet $\mathrm{P}_{2} \mathrm{Y}_{12}$ inhibition was assessed in whole blood using the VerifyNow P2Y12 system at least 20 minutes post-sampling. P2Y12 reactivity units (PRUs) and VerifyNow $\%$ inhibition (determined using the thrombin receptor-activating peptide channel results as estimated baseline response) were recorded. Evidence of $\mathrm{P}_{2} \mathrm{Y}_{12}$ inhibition was defined as VerifyNow \% inhibition $\geq 20 \%$.

Thromboelastometry was performed on a subset of patients recruited during working hours. This was performed according to the manufacturer's instructions using a ROTEM delta analyser and in-tem $S$ reagents (Tem Innovations). Clotting time, clot formation time, amplitude at 10 minutes and maximum clot firmness were recorded.

\section{Statistical Analysis}

A sample size of 19 with an $\alpha$ of 0.05 gives this study over $90 \%$ power to detect $25 \%$ drop in anti-Xa levels during the 6-hour infusion. Continuous data are presented as mean \pm standard error of the mean or median (interquartile range), as appropriate. Categorical data are presented as numbers and proportions. One-way analysis of variance (ANOVA) with Dunnett's multiple comparison tests was used for assessment of continuous variables. Effect of anti-emetic treatment on $\mathrm{P}_{2} \mathrm{Y}_{12}$ inhibition was assessed using two-way ANOVA. Results with $p$-values of $<0.05$ were considered statistically significant. Statistical analyses were performed using GraphPad Prism 7 for Mac OS X.

\section{Results}

\section{Study Population}

Twenty patients were recruited with median age of 67 years (-Table 1). Eighty per cent were males, $45 \%$ had anterior STEMI, all had PPCI through the radial artery approach and one patient required an intra-aortic balloon pump. All patients received a loading dose of $180 \mathrm{mg}$ ticagrelor pre$\mathrm{PPCI}$, administered as whole tablets. Nineteen patients completed the full enoxaparin regimen and were included in the pharmacodynamic analyses. No patient had an eGFR $<30$ $\mathrm{mL} / \mathrm{min}$. One patient was switched to tirofiban due to noreflow phenomenon after enoxaparin bolus but prior to starting enoxaparin infusion.

\section{Pharmacodynamic Assessments}

Anti-Xa levels peaked at the end of PPCI $(1.17 \pm 0.06 \mathrm{IU} / \mathrm{mL})$ and were subsequently sustained both 2 to 3 hours into infusion $(1.01 \pm 0.05 \mathrm{IU} / \mathrm{mL})$ and at the end of infusion $(1.003 \pm 0.06 \mathrm{IU} / \mathrm{mL})$ (- Fig. 1).

Pre-anti-coagulation, the turbidimetric assay demonstrated rapid fibrin clot formation with a lag time of
Table 1 Baseline, procedural and treatment characteristics

\begin{tabular}{|l|l|}
\hline Variable & Value \\
\hline Age (y, median [IQR]) & $67(57-77)$ \\
\hline Male sex (\%) & $16 / 20(80)$ \\
\hline Caucasian race (\%) & $18 / 20(90)$ \\
\hline Anterior STEMI (\%) & $9 / 20(45)$ \\
\hline Smoking (\%) & $12 / 20(60)$ \\
\hline Hypertension (\%) & $9 / 20(45)$ \\
\hline Diabetes mellitus (\%) & $3 / 20(15)$ \\
\hline Chronic kidney disease (\%) & $3 / 20(15)$ \\
\hline $\begin{array}{l}\text { Previous acute coronary } \\
\text { syndrome (\%) }\end{array}$ & $3 / 20(15)$ \\
\hline Previous PCI (\%) & $2 / 20(10)$ \\
\hline $\begin{array}{l}\text { Treatment with opiates } \\
\text { (morphine/diamorphine) }\end{array}$ & $18 / 20(90)$ \\
\hline $\begin{array}{l}\text { Pain to balloon time } \\
\text { (min, median [IQR]) }\end{array}$ & $205(131-364)$ \\
\hline $\begin{array}{l}\text { Call to balloon time } \\
\text { (min, median [IQR]) }\end{array}$ & $146(114-179)$ \\
\hline $\begin{array}{l}\text { Door to balloon time } \\
\text { (min, median [IQR]) }\end{array}$ & $22(14-30)$ \\
\hline Stent length (mm, median [IQR]) & $3.5(3-4)$ \\
\hline Stent diameter (mm, median [IQR]) & $60(50-95)$ \\
\hline $\begin{array}{l}\text { Ticagrelor loading to 1st blood } \\
\text { sampling (min, median [IQR]) }\end{array}$ & $185(175-220)$ \\
\hline $\begin{array}{l}\text { Ticagrelor loading to 2nd blood } \\
\text { sampling (min, median [IQR]) }\end{array}$ & $\begin{array}{l}\text { Ticagrelor loading to 3rd blood } \\
\text { sampling (min, median [IQR]) }\end{array}$ \\
\hline $\begin{array}{l}\text { Ticagrelor loading to 4th blood } \\
\text { sampling (min, median [IQR]) }\end{array}$ \\
\hline
\end{tabular}

Abbreviations: IQR, interquartile range; $\mathrm{PCl}$ : percutaneous coronary intervention; STEMI: ST-elevation myocardial infarction.

Note: Chronic kidney disease is defined as estimated glomerular filtration rate $(\mathrm{eGFR})<60 \mathrm{~mL} / \mathrm{min}$.

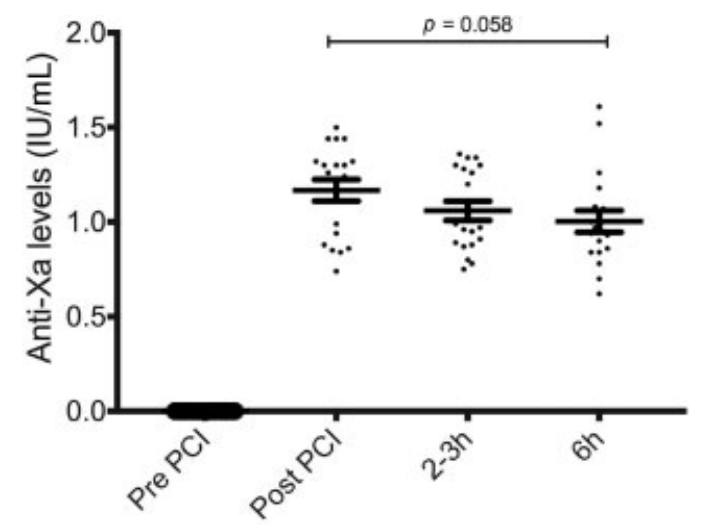

Fig. 1 Anti-Xa levels. A scatter plot demonstrating anti-Xa levels throughout the studied time points $(n=19)$. Variance during the infusion was assessed using one-way analysis of variance (ANOVA). Six hours versus 2 to 3 hours; $p=0.6$ and 6 hours versus post-PCI; $p=0.09$. Error bars represent mean \pm standard error of the mean (SEM). 


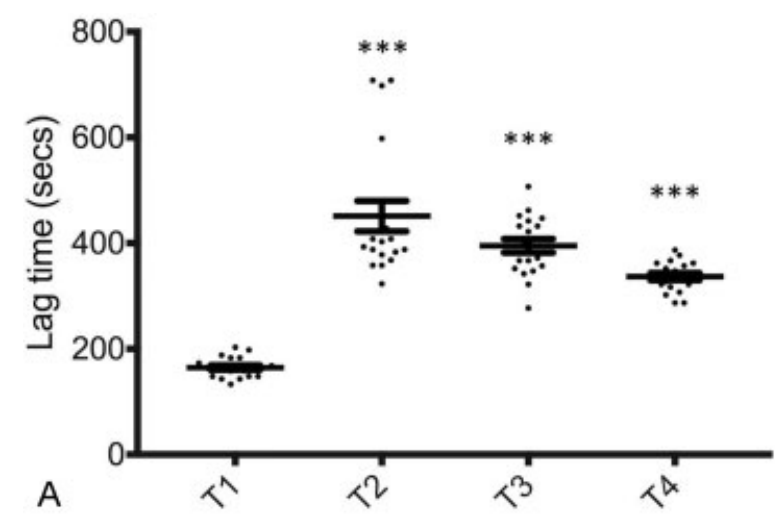
$n=19$
T1: Pre-anticoagulation
T2: End of PPCl
T3: 2-3 hours into infusion
T4: End of infusion
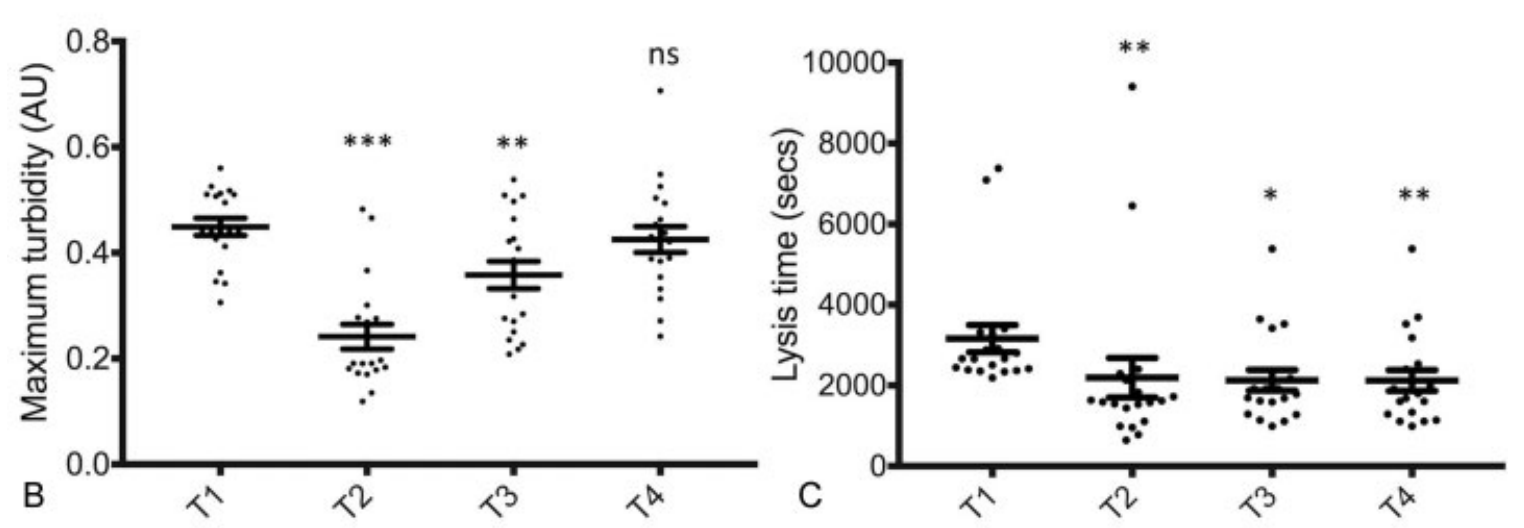

Fig. 2 The effects of enoxaparin on fibrin clot properties. Scatter plots demonstrating fibrin clot properties pre- and throughout treatment with enoxaparin. Error bars represent mean \pm standard error of the mean (SEM). AU, arbitrary unit; $\mathrm{PPCl}$, primary percutaneous coronary intervention. ${ }^{* * *}$ denotes $p<0.001,{ }^{* *}$ denotes $p<0.01,{ }^{*}$ denotes $p=0.01$; all compared with baseline (T1) and calculated using Dunnett's multiple comparisons tests.

$165 \pm 4.4$ seconds. This significantly prolonged at the end of PPCI (431 \pm 29 seconds; $p=0.0001$ vs. baseline) and remained prolonged during the infusion at 2 to 3 hours (395 \pm 13 seconds; $p=0.0001$ ) and at the end of infusion (337 \pm 6.6 seconds; $p=0.0001$ ) ( - Fig. 2 A).

Fibrin clot maximum turbidity measured was $0.45 \pm 0.02$ AU pre-anti-coagulation. This significantly dropped at the end of PPCI ( $0.24 \pm 0.02 \mathrm{AU} ; p=0.0001$ vs. baseline $)$ and gradually increased during the infusion $(0.36 \pm 0.03 \mathrm{AU}$; $p=0.0012$ vs. baseline) returning to baseline at the end of infusion ( $0.43 \pm 0.02 \mathrm{AU} ; \boldsymbol{p}=0.7$ vs. baseline) ( $\mathbf{- F i g}$. 2B).

Pre-anti-coagulation, lysis time measured 3,161 $\pm 339 \mathrm{sec}-$ onds. This significantly dropped by the end of $\operatorname{PPCI}(2,192 \pm 489$ seconds; $p=0.001$ vs. baseline) and remained low during the infusion (2,128 \pm 256 seconds; $p=0.014$ vs. baseline) and at the end of infusion $(2,124 \pm 259$ seconds; $p=0.009$ vs. baseline) (-Fig. 2C).

\section{Platelet P2Y $_{12}$ Inhibition}

All patients were $\mathrm{P}_{2} \mathrm{Y}_{12}$ inhibitor naive on presentation. Time from ticagrelor loading to different time points is summarized in - Table 1.

Using a PRU cut-off of $<208$ for evidence of $\mathrm{P}^{2} \mathrm{Y}_{12}$ inhibition, $12 / 19$ patients at the end of PPCI, 3/19 at 2 to 3 hours and $2 / 19$ patients at 6 hours had no $\mathrm{P}_{2} \mathrm{Y}_{12}$ inhibition. The two opiate-free patients had levels $<208$ by end of PPCI (-Fig. 3A).
Using VerifyNow \% inhibition, all but the two opiate-free patients had $0 \%$ inhibition by end of PPCI ( - Fig. 3B). Poor P2Y 12 inhibition remained common in morphine-treated patients throughout the 6-hour infusion with 8/19 patients still having $0 \%$ inhibition at 6 hours despite treatment with anti-emetics (metoclopramide \pm ondansetron) in all but 3 opiate-treated patients. Treatment with anti-emetics did not affect $\mathrm{P}_{2} \mathrm{Y}_{12}$ inhibition (interaction $p=0.26$ ). Only one patient vomited following ticagrelor's administration and was subsequently re-loaded with ticagrelor shortly after PPCI.

\section{Thromboelastometry}

Thromboelastometry was performed in a subset of 11 patients. Only clotting time was significantly prolonged throughout the infusion, whereas the other parameters were insensitive to the effects of enoxaparin ( - Supplementary Fig. S2, available in the online version).

\section{Clinical Outcomes}

None of the patients suffered any thrombotic or bleeding complication during the follow-up period (14-24 hours post$\mathrm{PPCI})$.

\section{Discussion}

We have studied the pharmacodynamic profile of a novel enoxaparin regimen in STEMI patients undergoing PPCI and 


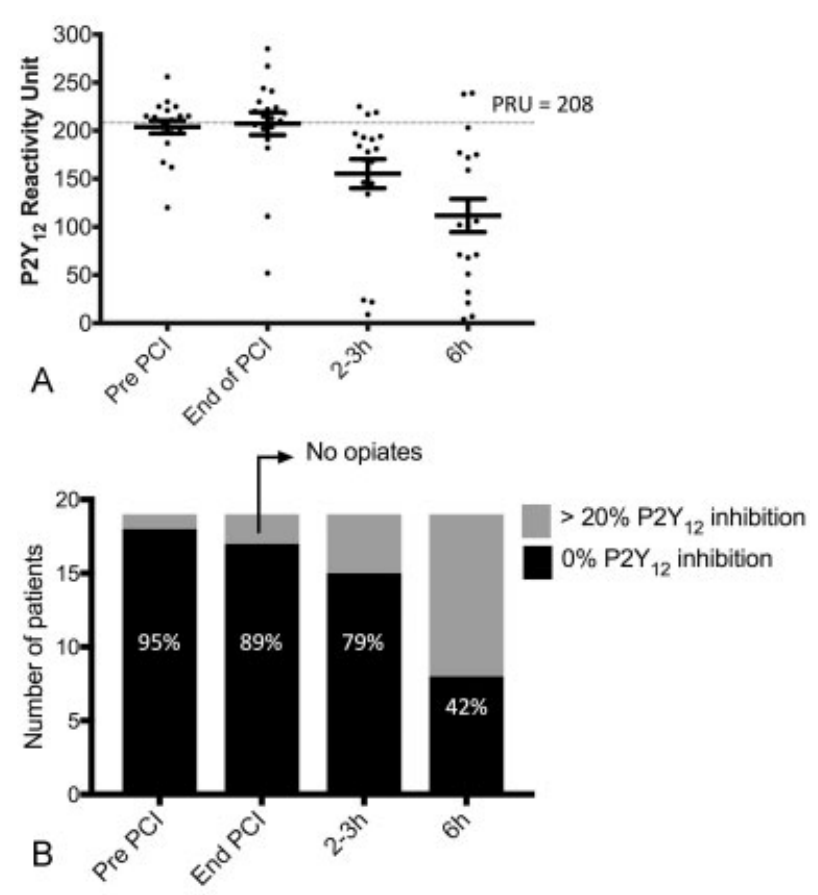

Fig. 3 Platelet $P 2 Y_{12}$ inhibition. (A) Scatter plot demonstrating the corresponding $\mathrm{P}_{2} \mathrm{Y}_{12}$ reaction units throughout the studied time points. Error bars represent mean \pm standard error of the mean (SEM). (B) Bar graph highlighting the number of patients with $0 \%$ inhibition as determined by VerifyNow. Two patients did not receive opiates and had $>20 \%$ inhibition by the end of $\mathrm{PCl}$ (as indicated by arrow).

have shown that it results in sustained anti-Xa levels throughout the 6-hour infusion. This regimen positively modulated fibrin clot properties, prolonging lag time and improving lysis potential, indicating the formation of less thrombotic clots. ${ }^{29,30}$ Inefficient lysis is an independent predictor of cardiovascular death following MI and so this regimen might help to improve prognosis. ${ }^{31}$ The universal prolongation of lag time following enoxaparin was prominent and consistent throughout, which may provide a useful functional measure of response to this therapy. Interestingly, fibrin clot studies provided more consistent data compared with thromboelastometry, suggesting a higher sensitivity of this method for detecting the anti-thrombotic effects of enoxaparin.

Delayed absorption of oral $\mathrm{P}^{2} \mathrm{Y}_{12}$ inhibitors in STEMI patients is increasingly recognized by interventional cardiologists as a stent thrombosis risk. Crushing tablets have been attempted as a way to accelerate absorption of oral $\mathrm{P}_{2} \mathrm{Y}_{12}$ inhibitors. ${ }^{32-35}$ However, results were marginal and delayed absorption in a proportion of STEMI patients remains a risk. Similarly, increasing ticagrelor's loading dose did not overcome the problem. ${ }^{36}$ Therefore, parenteral therapies are likely to be needed to protect a large majority of patients.

This novel enoxaparin regimen has the advantage of being simple and easy to implement in an emergency situation. Enoxaparin is also widely used for many other indications with good tolerability. Moreover, it is inexpensive and therefore likely to offer substantial cost savings when compared with GPIs or cangrelor.

We should acknowledge the limitations of our study. This is a single-arm pharmacodynamic study and clinical outcomes are only reported as pilot outcomes. Larger randomized studies are needed to establish the safety and efficacy of the studied enoxaparin regimen in STEMI patients undergoing PPCI. Furthermore, platelet $\mathrm{P}_{2} \mathrm{Y}_{12}$ inhibition was only studied with one methodology although we have found this methodology to be most discriminatory in the assessment of platelet $\mathrm{P}_{2} \mathrm{Y}_{12}$ inhibition. ${ }^{37}$ Our study has sufficient power to detect $25 \%$ drop in anti-Xa levels at the two time points. The degree of variance in anti-Xa levels is of borderline significance $(p=0.058)$ but levels at the end of infusion remained therapeutic, resulting in sustained improvement in fibrin clot lysis potential. A high percentage of patients had poor platelet inhibition by the end of infusion, which raises the possibility that the duration of infusion might not be sufficient. However, enoxaparin's halflife is approximately 2 hours and more $\mathrm{P}^{2} \mathrm{Y}_{12}$ inhibition is highly likely to be established by 8 hours after loading dose of ticagrelor. This requires further assessment in future work.

\section{Conclusion}

A bolus dose of enoxaparin $(0.75 \mathrm{mg} / \mathrm{kg})$ followed by an infusion of $0.75 \mathrm{mg} / \mathrm{kg} / 6 \mathrm{~h}$ results in sustained pharmacodynamic effects throughout the infusion in STEMI patients undergoing PPCI. The efficacy and safety of this regimen should be evaluated in larger studies.

\section{What is known about the topic?}

- Platelet $\mathrm{P}^{2} \mathrm{Y}_{12}$ inhibition is often delayed in opiatetreated STEMI patients undergoing PPCI.

- This delay in platelet inhibition may increase the risk of stent thrombosis.

- Strategies to manage this risk are needed.

\section{What does this paper add?}

- A novel regimen of enoxaparin $(0.75 \mathrm{mg} / \mathrm{kg}$ bolus followed by $0.75 \mathrm{mg} / \mathrm{kg} / 6 \mathrm{~h}$ ) in STEMI patients undergoing PPCI results in sustained anti-Xa levels.

- This regimen positively modulates fibrin clot properties, prolonging fibrin clot lag time, reducing fibrin clot density and enhancing lysis potential.

- This regimen may offer an inexpensive solution to the delayed absorption of oral $\mathrm{P}_{2} \mathrm{Y}_{12}$ inhibitors but future studies are needed to confirm safety and efficacy.

\section{Funding}

This study was funded through a British Heart Foundation clinical research training fellowship for Dr Wael Sumaya (FS/15/82/31824).

\section{Conflict of Interest}

R.F.S. reports research grants from AstraZeneca, PlaqueTec; Honoraria from AstraZeneca; Consultant/Advisory Board fees from AstraZeneca, Actelion, Avacta, Bayer, 
Bristol Myers Squibb/Pfizer, Idorsia, Novartis and The Medicines Company. Other authors have no disclosures.

\section{Acknowledgments}

We are grateful for the support we received from Eileen Quinn and colleagues in the Cardiac Catheter Suite at the Northern General Hospital; Dr Erica Wallis and Dr Nana Theodorou in the Clinical Research and Innovation Office and Kim Ryalls in the Pharmacy Department, Sheffield Teaching Hospitals NHS Foundation Trust; Claire Bridge, Patricia Shaw and Hannah McMellon in the Cardiovascular Research Unit, University of Sheffield; and Professor Alistair S. Hall from the University of Leeds for chairing the Data Monitoring Committee.

\section{References}

1 Ibanez B, James S, Agewall S, et al; ESC Scientific Document Group. 2017 ESC guidelines for the management of acute myocardial infarction in patients presenting with ST-segment elevation: the Task Force for the management of acute myocardial infarction in patients presenting with ST-segment elevation of the European Society of Cardiology (ESC). Eur Heart J 2018;39(02):119-177

2 Wiviott SD, Braunwald E, McCabe CH, et al; TRITON-TIMI 38 Investigators. Prasugrel versus clopidogrel in patients with acute coronary syndromes. N Engl J Med 2007;357(20):2001-2015

3 Wallentin L, Becker RC, Budaj A, et al; PLATO Investigators. Ticagrelor versus clopidogrel in patients with acute coronary syndromes. N Engl J Med 2009;361(11):1045-1057

4 Wiviott SD, Trenk D, Frelinger AL, et al; PRINCIPLE-TIMI 44 Investigators. Prasugrel compared with high loading- and maintenance-dose clopidogrel in patients with planned percutaneous coronary intervention: the Prasugrel in Comparison to Clopidogrel for Inhibition of Platelet Activation and Aggregation-Thrombolysis in Myocardial Infarction 44 trial. Circulation 2007;116 (25):2923-2932

5 Gurbel PA, Bliden KP, Butler K, et al. Randomized double-blind assessment of the ONSET and OFFSET of the antiplatelet effects of ticagrelor versus clopidogrel in patients with stable coronary artery disease: the ONSET/OFFSET study. Circulation 2009;120 (25):2577-2585

6 Thomas MR, Morton AC, Hossain R, et al. Morphine delays the onset of action of prasugrel in patients with prior history of STelevation myocardial infarction. Thromb Haemost 2016;116(01): 96-102

7 Alexopoulos D, Xanthopoulou I, Gkizas V, et al. Randomized assessment of ticagrelor versus prasugrel antiplatelet effects in patients with ST-segment-elevation myocardial infarction. Circ Cardiovasc Interv 2012;5(06):797-804

8 Kubica J, Adamski P, Ostrowska M, et al. Morphine delays and attenuates ticagrelor exposure and action in patients with myocardial infarction: the randomized, double-blind, placebo-controlled IMPRESSION trial. Eur Heart J 2016;37(03):245-252

9 Parodi G, Bellandi B, Xanthopoulou I, et al. Morphine is associated with a delayed activity of oral antiplatelet agents in patients with ST-elevation acute myocardial infarction undergoing primary percutaneous coronary intervention. Circ Cardiovasc Interv 2014;8(01):8

10 Silvain J, Storey RF, Cayla G, et al. P2Y12 receptor inhibition and effect of morphine in patients undergoing primary PCI for STsegment elevation myocardial infarction. The PRIVATE-ATLANTIC study. Thromb Haemost 2016;116(02):369-378

11 Gosling R, Yazdani M, Parviz Y, et al. Comparison of $\mathrm{P}_{2} \mathrm{Y}_{12}$ inhibitors for mortality and stent thrombosis in patients with acute coronary syndromes: single center study of 10793 consecutive 'real-world' patients. Platelets 2017;28(08):767-773

12 Siller-Matula JM, Specht S, Kubica J, et al. Abciximab as a bridging strategy to overcome morphine-prasugrel interaction in STEMI patients. Br J Clin Pharmacol 2016;82(05):1343-1350

13 Storey RF, Sinha A. Cangrelor for the management and prevention of arterial thrombosis. Expert Rev Cardiovasc Ther 2016;14(09): 991-999

14 De Luca G, Navarese E, Marino P. Risk profile and benefits from Gp IIb-IIIa inhibitors among patients with ST-segment elevation myocardial infarction treated with primary angioplasty: a metaregression analysis of randomized trials. Eur Heart J 2009;30 (22):2705-2713

15 Stone GW, Witzenbichler B, Guagliumi G, et al; HORIZONS-AMI Trial Investigators. Bivalirudin during primary $\mathrm{PCI}$ in acute myocardial infarction. N Engl J Med 2008;358(21):2218-2230

16 Steg PG, van 't Hof A, Hamm CW, et al; EUROMAX Investigators. Bivalirudin started during emergency transport for primary $\mathrm{PCI}$. N Engl J Med 2013;369(23):2207-2217

17 Stone GW, McLaurin BT, Cox DA, et al; ACUITY Investigators. Bivalirudin for patients with acute coronary syndromes. N Engl J Med 2006;355(21):2203-2216

18 Rao SV, Ohman EM. Anticoagulant therapy for percutaneous coronary intervention. Circ Cardiovasc Interv 2010;3(01):80-88

19 Sanchez-Pena P, Hulot JS, Urien S, et al. Anti-factor Xa kinetics after intravenous enoxaparin in patients undergoing percutaneous coronary intervention: a population model analysis. $\mathrm{Br} \mathrm{J}$ Clin Pharmacol 2005;60(04):364-373

20 Montalescot G, Cohen M, Salette G, et al; STEEPLE Investigators. Impact of anticoagulation levels on outcomes in patients undergoing elective percutaneous coronary intervention: insights from the STEEPLE trial. Eur Heart J 2008;29(04):462-471

21 Eika C. Inhibition of thrombin induced aggregation of human platelets by heparin. Scand J Haematol 1971;8(03):216-222

22 Judge HM, Jennings LK, Moliterno DJ, et al. PAR1 antagonists inhibit thrombin-induced platelet activation whilst leaving the PAR4-mediated response intact. Platelets 2015;26(03):236-242

23 Storey RF, May JA, Heptinstall S. Potentiation of platelet aggregation by heparin in human whole blood is attenuated by P2Y12 and P2Y1 antagonists but not aspirin. Thromb Res 2005;115(04):301-307

24 Xiao Z, Théroux P. Platelet activation with unfractionated heparin at therapeutic concentrations and comparisons with a low-molecular-weight heparin and with a direct thrombin inhibitor. Circulation 1998;97(03):251-256

25 Montalescot G, Zeymer U, Silvain J, et al; ATOLL Investigators. Intravenous enoxaparin or unfractionated heparin in primary percutaneous coronary intervention for ST-elevation myocardial infarction: the international randomised open-label ATOLL trial. Lancet 2011;378(9792):693-703

26 Lincoff AM, Tcheng JE, Califf RM, et al; PROLOG Investigators. Standard versus low-dose weight-adjusted heparin in patients treated with the platelet glycoprotein IIb/IIIa receptor antibody fragment abciximab (c7E3 Fab) during percutaneous coronary revascularization. Am J Cardiol 1997;79(03):286-291

27 Franchi F, Rollini F, Cho JR, et al. Effects of dabigatran on the cellular and protein phase of coagulation in patients with coronary artery disease on dual antiplatelet therapy with aspirin and clopidogrel. Results from a prospective, randomised, doubleblind, placebo-controlled study. Thromb Haemost 2016;115 (03):622-631

28 Carter AM, Cymbalista CM, Spector TD, Grant PJ; EuroCLOT Investigators. Heritability of clot formation, morphology, and lysis: the EuroCLOT study. Arterioscler Thromb Vasc Biol 2007; 27(12):2783-2789

29 Ajjan RA, Ariëns RA. Cardiovascular disease and heritability of the prothrombotic state. Blood Rev 2009;23(02):67-78

30 Alzahrani SH, Ajjan RA. Coagulation and fibrinolysis in diabetes. Diab Vasc Dis Res 2010;7(04):260-273 
31 Sumaya W, Wallentin L, James SK, et al. Fibrin clot properties independently predict adverse clinical outcome following acute coronary syndrome: a PLATO substudy. Eur Heart J 2018;39(13): 1078-1085

32 Niezgoda P, Sikora J, Barańska M, et al. Crushed sublingual versus oral ticagrelor administration strategies in patients with unstable angina. A pharmacokinetic/pharmacodynamic study. Thromb Haemost 2017;117(04):718-726

33 Rollini F, Franchi F, Hu J, et al. Crushed prasugrel tablets in patients with STEMI undergoing primary percutaneous coronary intervention: the CRUSH Study. J Am Coll Cardiol 2016;67(17): 1994-2004

34 Teng R, Carlson G, Hsia J. An open-label, randomized bioavailability study with alternative methods of administration of crushed ticagrelor tablets in healthy volunteers. Int J Clin Pharmacol Ther 2015;53(02):182-189

35 Parodi G, Xanthopoulou I, Bellandi B, et al. Ticagrelor crushed tablets administration in STEMI patients: the MOJITO study. J Am Coll Cardiol 2015;65(05):511-512

36 Franchi F, Rollini F, Cho JR, et al. Impact of escalating loading dose regimens of ticagrelor in patients with ST-segment elevation myocardial infarction undergoing primary percutaneous coronary intervention: results of a prospective randomized pharmacokinetic and pharmacodynamic investigation. JACC Cardiovasc Interv 2015;8(11):1457-1467

37 Storey RF, Angiolillo DJ, Bonaca MP, et al. Platelet inhibition with ticagrelor $60 \mathrm{mg}$ versus $90 \mathrm{mg}$ twice daily in the PEGASUS-TIMI 54 Trial. J Am Coll Cardiol 2016;67(10):1145-1154 